\title{
The Order in The Structure of Motives of Activity: Quantitative Description
}

\author{
Yulia A. Mochalova ${ }^{1 *}$ \\ ${ }^{1}$ Faculty of Psychology, Pedagogy and Defectology, Don State Technical University, Rostov-on-Don, Russian Federation, \\ e-mail: guliya@mail.ru
}

\begin{abstract}
The purpose of the study is to conduct an empirical verification of the validity of the theoretical assumption that there is an order in the structure of motives of activity, which is determined by the proportionality between the significance of each motive in their aggregate significance and is quantitatively manifested in the parameters of the hyperbolic $\mathrm{H}$-distribution ranked by the parameter. The necessary conditions for solving this problem are highlighted: a) structural elements - weakly functionally dependent on each other motives; $b$ ) in the structure of motives, the functional significance of each has a quantitative expression, which must be measured through the organization of empirical research; c) the measure of the total functional significance of all motives is limited by the situation of activity and the costs of obtaining its product. On a sample of students of the first, second, third, fourth courses of technical and humanitarian specialties $(\mathrm{N}=860)$ using the method of subjective assessment of the significance of each of the three motives for studying at the university in their combined significance ("acquisition of knowledge"; "mastering a profession"; "obtaining a diploma") and using a given level of the average error of approximation of empirical results with an $\mathrm{H}$-distribution of $10 \%$, it was found that statistically, at a level of error probability less than $20 \%$, students with an average error below a given level predominate. The possible formal and substantive reasons that led to a decrease in the validity of the result are named. The interpretation of the results in the context of the "junction" of systems theory and activity theory is presented. The directions of further research in the context of the proposed model are determined.

Keywords: activity, motive, system, structure, structure order, model validity.
\end{abstract}

\section{Introduction}

Taking into consideration the degree of development of the problem and understanding by this the number of different information sources on this topic, it can be argued that the study of human motivation, along with the problem of personality, occupies a leading place in Russian psychology according to this parameter. There is a huge number of different kinds of such sources, which reflect certain aspects of the study of the motivation of a person. These are monographs (Badmaeva, 2004; Leontiev, 2002 etc.), doctoral dissertations (Gordeeva, 2013; Orlov, 1984 etc.) and a huge number of articles, theses in various collections, journals. Our article is connected not so much with an attempt to introduce elements of mathematisation into a systematic approach to the study of motivation in the theory of activity, as with a desire to move away from the analytical (elemental) approach in this "segment" of psychological research (various types of regression analysis, multidimensional analysis, including factor analysis) and to present a mathematized model of studying the order in the structure of motives of activity, determined by the quantitative balance between the motives forming the structure and interpreted in the context of the methodology of self-organization.

The choice of the order of the structure of the motives of activity as the subject of mathematical description is due to the following factors. A structure exists where there are not one, but several elements potentially capable of forming it. For example, the purpose of an activity cannot form a structure, because it is always the same. And also, A. N. Leontiev's understanding of the motive as an objectified need and, at the same time, the fact that "In the very need state of the subject, the object that is able to satisfy the need is not rigidly recorded......" (Leontiev, 1983). It can be assumed that the same need can be satisfied by different objects (motives), and the activity itself is always potentially polymotivated, which potentially can 
form a structure. Our point of view regarding the interpretation of the polymotivation of activity differs from the point of view of a number of domestic psychologists. So D. A. Leontiev interprets the polymotivation of activity as "not that one activity has several motives, but that, as a rule, several needs are identified in one motive to varying degrees" (Leontiev, 2016). Further, we can say that one of the most important factors (others are, such as the situation, the goal, etc.) determining the future structure of motives is the ability of each motive (object) to satisfy the need. In the ratio of these abilities of objects to satisfy the need, a structure of motives arises, including through self-organization, which will be characterized by a certain order. The order in the structure of motives will determine the effectiveness of the activity.

The motives that are present at the same time and which are much more strongly connected with the need than with each other, and at the same time each individual is able to satisfy this need to some extent, it is necessary to correlate with each other in their structural totality. We will call them functionally autonomous motives, since, hypothetically, each of them individually can satisfy the need (fulfill its function) and, as a result, they are relatively autonomous, but in reality they are, albeit weakly, but connected to each other. For example, highlighted A. N. Leontiev's sense-forming motives and motives - stimuli are not such, because the main function of the motive-stimulus is not aimed at satisfying the need that determines the activity, but to "accelerate" the movement towards the sense-forming motive. It is worth paying special attention to the fact that it is a very difficult task to identify truly functionally autonomous motives that determine a specific type of activity. It was possible to follow the empirical path, through statistical factorization (FA), since it is based on orthogonal rotation of factors, which gives statistical independence, but, firstly, what elements can we take as the basis of such a factor model, secondly, there will be a problem with adequate measurement of these elements and, thirdly, no real model explains even $70 \%$ of the total elements. For example, in the context of the object field of our research (students), D.Ts. Badmaeva, as a result of a survey of students and subsequent factorization, identified 7 motives for learning: 1) avoiding failure; 2) prestige; 3) creative self-realization; 4) social; 5) educational and cognitive; 6) communicative; 7) professional (Badmaeva, 2004). However, when you get acquainted with the characteristics of each motive presented by the author, you see that there is no functional autonomy between the motives. For example, the prestige motive and the social motive are functionally strongly related to each other the latter being in its turn related to the communicative motive.

The question arises - how to empirically measure in the structure of motives the ratio between the significance of each of them in their aggregate significance in order to quantitatively reflect the features of the order in the structure. We believe that this can be done by a special organization of a research situation in which the subjects, using a subjective assessment, will quantitatively correlate the measure of significance of each motive in their totality and distribute points in accordance with this assessment. It is only necessary to take into account the fact that the general measure of the significance of motives in their totality is not limited by the need of the subject of activity, but is limited by the situation in which the activity unfolds. For example, the measure of the cumulative functional significance of motives is limited by the price of error in this activity - the higher the price of error, the more limited the overall measure.

According to the mathematical description of the order in the structure of motives of activity, we can assume that the order may manifest itself in the parameters of hyperbolic distributions, which have long been used in the study of self-organization processes in such scientific disciplines as sociology (Pareto, 2008), pedagogy (Gurina, 2017), philology (Arapov and Schrader, 1978) and which have begun to be tested in psychological research (Dorofeev, 2019; Dorofeev and Mochalova, 2015).

We believe that to study the order in the structure of activity motives, it is necessary to use a hyperbolic $\mathrm{H}$-distribution ranked by parameter (parameter is the significance of each motive in their aggregate significance) (Kudrin, 2002). Distribution formula:

$$
\mathrm{W}=\frac{\mathrm{A}}{\mathrm{r}^{\beta}},+\mathrm{B}
$$

$\mathrm{W}$ - is the parameter by which objects are ranked (the significance of the motive); $r$ - is the rank number of the motive $(1,2,3 \ldots) ; A$ - is a constant value equal to the maximum value of the measure of expression of the most significant motive in the structure having 1 rank; $\beta$ is the rank coefficient characterizing the degree of steepness of the hyperbola; $B$ is a constant.

In order to verify the theoretical assumptions put forward, we conducted an empirical study in which we assumed that if our assumptions are correct, then at the level of empiricism this fact should manifest itself in the coincidence of the empirical (real) $\mathrm{H}$-distributions of the intensity of motives in a structure with a theoretical (ideal) calculated by the hyperbolic regression equation. However, for this it is necessary: firstly, to apply to a specific type of activity, and secondly, on a large sample volume. The 
statistical solution to this problem can be the average approximation error (s). Due to the fact that the statistical reliability of $s$ cannot be determined, we used a standard that is found most often in the literature on regression modeling, namely, $s=10 \%$. The whole sample was divided into two ( 1 sample $-\mathrm{s} \leq 10 \%, 2$ sample - $s>10 \%$ ).

The empirical hypothesis of the study: the motives of students' learning activities form a structure, the order of which is manifested in a hyperbolic H-distribution ranked by parameter (parameter - the significance of each motive in their aggregate significance).

Due to the fact that testing such a hypothesis requires special attention to statistical analysis, we considered it reasonable to formulate statistical hypotheses - null and alternative.

Statistical hypotheses: $\mathrm{HO}$ - students with an average approximation error (s) below the acceptable level $(s \leq 10 \%)$ will not statistically significantly prevail over students with $s$ above the acceptable level $(s>10 \%)$. $\mathrm{H1}$ - students with an average approximation error (s) below the acceptable level (s $\leq 10 \%)$ will statistically significantly prevail over students with s above the acceptable level ( $s>10 \%)$.

\section{Materials and Methods}

1) To study the polymotivational structure of students' learning activities, we used the motives identified by T.I. Ilyina, which could potentially form this structure - 1) "acquisition of knowledge"; 2) "mastering a profession"; 3) "obtaining a diploma" (llyin, 2015). Our choice was due to the fact that this classification, as it seems to us, is most suitable for the criterion of "functional autonomy of the motives of educational activity", although we understand that there is a functional connection between them. Before the measurement, the subjects were given the following definitions of the content of motives: 1) the motive of "acquiring knowledge" - the desire to acquire knowledge, curiosity; motive; 2) the motive of "mastering a profession" - the desire to acquire professional knowledge and form professionally important qualities; 3 ) the motive of "obtaining a diploma" - the desire to acquire a diploma with formal assimilation of knowledge.

2) In order to study the proportionality between the significance of each motive in their aggregate significance in the polymotivational structure of educational activity, students were asked to distribute a fixed sum of 21 points $(7 \times 3=1)$ between the three above-mentioned motives, in accordance with the subjective ideas of the subject about the above-mentioned significance. Instruction to the subjects: "You are offered 21 points for three motives of learning. Your task is to correlate them with each other according to the degree of significance and distribute them according to their significance." The choice of such a number of points was due to two factors. Firstly, since the basis of the measuring procedure was the method of subjective scaling, in which the low dimension of the scale gives poorly differentiable results, and the high one does not give an increase in accuracy, the maximum value was chosen at 7 points. Secondly, the analysis of numerous research papers carried out using the questionnaire by T. I. Ilyina showed that there is a linear relationship between the motives, therefore, their interaction is additive, which is reflected in their sum.

\section{Methods of statistical and mathematical analysis}

To find the parameters of the hyperbolic H-distribution ranked by the parameter, the computer program SPSS 17.0 (module "Curve fitting") was used. To determine the measure of the discrepancy between the empirical values and the values calculated by the regression equation, the average approximation error (s) was used. For statistical evaluation of the reliability of the differences in the frequency of occurrence of subjects in two groups differentiated by level $\mathrm{s}$, a non $x^{2}$ rametric criterion for dichotomy adjusted for continuity was used.

\section{Study participants}

A total of 860 students of DSTU were examined. To increase the representativeness of the results, we took into account two factors when forming the sample: 1$)$ the course of study $\left(1^{\text {st }}, 2^{\text {nd }}, 3^{\text {rd }}, 4^{\text {th }}\right)$ and the specialty received at the university (technical, humanitarian).

\section{Results}

After finding the parameters of hyperbolic distributions for all subjects $(\mathrm{N}=860)$, ideal (theoretical) values of severity corresponding to these parameters in the structure of motives of each motive were calculated and average approximation errors were found with rounding to 0.1 (values $<0.05$ were rounded down, and values $\geq 0.05$ were rounded up). The accumulated frequencies of the subjects in two samples 
differentiated by the criterion $s \leq 10 \%$ and $s>10 \%$ are shown in Figure 1.

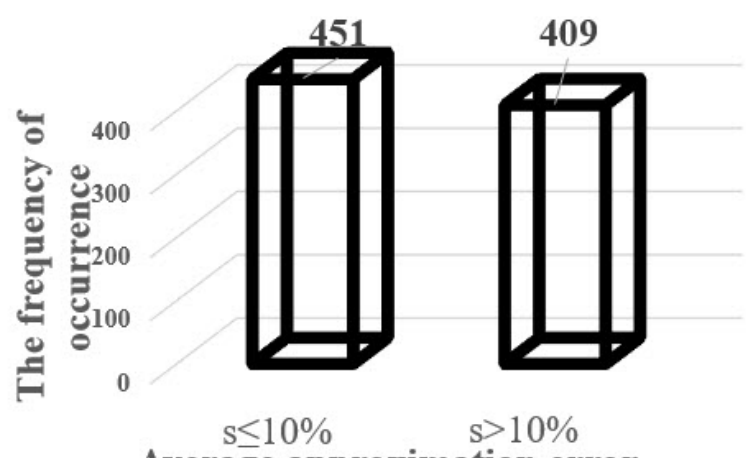

Average approximation error

Figure 1. Diagram of the frequency of occurrence of students with $s \leq 10 \%$ and $s>10 \%$ in the hyperbolic $\mathrm{H}$-distribution ranked by parameter (parameter is the severity of the motives of educational activity in their totality)

Figure 1 shows that the frequency of occurrence of those students with $s \leq 10 \%(n=451)$ is higher compared to those with $s>10 \%(n=409)$. Checking the statistical reliability of the significance of the differences in empirical frequencies showed that $\chi^{2}$-empirical $(1,954)$ is greater than $\chi^{2}$-tabular at $p$ $\leq 0.2(1,642)$ and, as a consequence, the frequency of occurrence of those students whose average approximation error is $\leq 10 \%$ is statistically significantly higher than the frequency of occurrence of those students who have it $>10 \%$ with an error probability of no more than $20 \%$. Let's give a statistical interpretation of the result obtained. The presence of three statistical conditions, namely: 1) the use of "low reliable" nonparametric statistics, especially related to dichotomy; 2) exceeding the acceptable level of error probability in psychology by $5 \%$ and 3 ) the lack of statistical verification of the reliability of the average approximation error, forces us to accept the statistical hypothesis $\mathrm{H} 0$ and say that the structure of motives for educational activity cannot be described by a hyperbolic $\mathrm{H}$-distribution ranked by parameter. However, it can be assumed that there are some statistical refinements.

To do this, we decided to visualize the accumulated empirical frequencies of the occurrence of the average approximation error (s) in the combined sample.

For clarity, the smoothed curve of the polygon of accumulated empirical frequencies of occurrence of the average approximation error (s) with rounding to 0.1 (values $<0.05$ were rounded down, and values $\geq 0.05$ were rounded up) in the combined sample is shown in Figure 2 .



Figure 2. The smoothed curve of the polygon of accumulated frequencies of the average approximation error in the hyperbolic $\mathrm{H}$-distribution ranked by the parameter (the parameter is the severity of the motives of educational activity in their totality) in the combined sample.

Visual analysis of the data presented in Figure 2 gives us reason to assume that the validity of the above result could be reduced by the following factors.

Firstly, the features of the nature of the distribution reflected in the smoothed curve of the polygon of accumulated empirical frequencies. Visually, it differs from normal (for the application of the $\chi^{2}-$ criterion is a prerequisite) and may be lognormal. To test our assumption, we calculated the indicators of the mean, mode and median. The ratio of their values, expressed in the fact that the median (9.1) is located to the left of the mean (10.7), but to the right of the mode (9) only confirmed our assumption. And the lognormal distribution qualitatively characterizes a sample in which most of the subjects have low values, and a 
relatively insignificant one has too high values. As a consequence, the division of students "on the edge" $s=10 \%$ could reduce the validity of the manifestation of $s$ in the entire sample.

Secondly, it is not possible to check the statistical reliability of the average approximation error. We must rely on the operation of the "statistical law of large numbers". And if in terms of sample size $(n=860)$ our study relatively meets this requirement, then in terms of the number of elements in the structure under study (in our case 3 ) it does not.

Thirdly, the differentiation of the subjects into two groups by an average approximation error of $10 \%$ did not allow taking into account the fact that a large number of subjects turned out to be "above or below" this indicator, not because it really is, due to the effect of the "number of decimal places".

Fourth, the presence of an increase in the frequency of occurrence of subjects (up to 8-9 subjects for each value of the average approximation error) in its interval [20\% - 22\%]. This may be a random fact, or it may have some kind of pattern and in the future it will be necessary to conduct an empirical study of the qualitative specifics of this contingent of subjects.

\section{Discussions}

Due to the fact that the study was carried out "at the junction" of systems theory and activity theory, we will try to "interpretatively integrate" the methodologies of these theories in a meaningful interpretation of the empirical results.

Firstly, although A. N. Leontiev gives priority to motives in the genesis and implementation of activities, nevertheless, contextually motives always correspond to them with purpose and meaning (which is required by the principle of unity of consciousness and activity). The "presence" in the activity of not only motives, but goals and meaning, most likely, manifests itself in the order of the structure of motives (in our study, the motives of students' learning activities). Taking into account this fact, we conclude that the order in the structure of the motives of educational activity of students is a product of both the process of self-organization, which is a consequence of the proportionality between the motives of educational activity, and the process of purposeful, which is a consequence of the presence of meaning and purpose in educational activity. In their aggregate dynamics, the processes of self-organization and purposefulness can be codirected, alternative (for example, due to the action of situational and subjective factors, motives form a structure that does not "agree" with the teaching goal imposed by teachers on students) and relatively autonomous.

Secondly (a consequence of the first), the result we have obtained gives us reason to believe that the study of the role of the systemic organization of activity in the "movement" to its meaning should begin with the level of motives, and not the level of needs, as a number of authors believe, considering that polymotivation is generated by the "convergence" of several needs in one object (Gerasimov, 2002; Leontiev, 2016; Leontiev, 1993 etc.).

\section{Conclusions}

If we follow strict statistical requirements, then we must admit that in our study we have not proved an alternative hypothesis at a sufficient level of significance and must accept zero - students with an average approximation error below the acceptable level $(s \leq 10 \%)$ do not statistically significantly prevail over students with such an error above the acceptable level ( $s>10 \%)$. However, as it was shown when analyzing such a situation, there are factors (the "weakness" of nonparametric statistics, the absence of a normal distribution of the trait in the combined sample, relatively low elaboration of diagnostic material and measurement procedures, etc.) that do not give grounds to abandon not only the study of the order in the structure of motives, but also the use of a hyperbolic $\mathrm{H}$-distribution ranked by parameter. This fact gives us grounds to identify promising areas for further research.

\section{Direction of further research}

1) Due to the fact that in the interpretation of the results of studies related to the use of hyperbolic distributions, an important role is assigned to specific values of parameters, especially the coefficient $\beta$, which not only reflect important characteristics of the properties of the system, but allow you to predict its development, in the future it is interesting to study:

- the basic dynamics of changes in the order of the structure of motives - either from order to chaos (classical entropy model), or from chaos to order (Ludwig von Bertalanfi model);

- the presence of not fully realized motives in the structure; 
- the potential possibility of including new motives in the structure.

2) Recently, more and more attention has been paid in psychology to the study of meaning in human life. Now there are many works in which we encounter such concepts as "meaning formation", "meaning creation", "finding meaning". Within this framework, it seems promising to study the role of order in the structure of motives at each stage of the formation of meaning, which can be both direct - the content of motives and the order of their structure generate the content of meaning, and indirect - the content of motives and the order of their structure manifest themselves in the stages of the formation of meaning.

\section{Acknowledgements}

The authors would like to thank everyone who contributed to this article.

\section{Conflict of interests}

The author declares no conflict of interest.

\section{References}

Arapov, M., \& Shrejder, Y. (1978). Zakon cipfa i princip dissimmetrii sistem [Zipf's law and system dissymmetry principle]. Semiotics and informatics, 10, 74-95.

Badmaeva, N. T. (2004). Motivation of mental activity: a monograph. Publishing House of VSSTU. Retrieved from http:// window.edu.ru/resource/940/18940/files/Mtdusc10.pdf

Bartholomew, D. J. (1982). Stochastic Models for Social Processes (Wiley Series in Probability and Statistics - Applied Probability and Statistics Section) ( $3^{\text {rd }}$ ed.). Wiley. Retrieved from https://scask.ru/r_book_stsc.php

Bertalanffy L. von. (1969). General Theory of Systems - critical review. George Braziller, Inc

Dorofeev, V. A. (2019). A systematic view of the problem of trust in the manager in the organization. Azimuth of Scientific Research: Pedagogy and Psychology, 8(1(26)), 113-117. Retrieved from https://www.elibrary.ru/download/ elibrary_37130010_66657540.pdf

Dorofeev, V. A., \& Mochalova, J. A. (2015). Symmetry - Asymmetry of Generic Structure Order of the "Worldview" as Seen by the Russians, Italians and Frenchmen. Mediterranean Journal of Social Sciences, 6(4), 419. https://doi.org/10.5901/ mjss.2015.v6n4s1p419

Gerasimov, A. V. (2002). Motivation to work in the context of the theory of psychological systems. Siberian Psychological Journal, 16-17, 13-17. Retrieved from http://journals.tsu.ru/psychology/\&journal_page=archive\&id=1402\&article_ id $=27911$

Gordeeva, T. O. (2013). Motivation of educational activity of schoolchildren and students: structure, mechanisms, conditions of development: Reglet. Retrieved from https://viewer.rusneb.ru/ru/rs101005533356?page=1\&rotate=0\&theme=white

Gurina, R. V. (2017). On inclusion of cenological knowledge in education. Professional Education in the Modern World, 7(3), 1246-1252. https://doi.org/10.15372/pemw20170315

llyin, E. P. (2015). Motivation and motives. Peter. Retrieved from https://www.universalinternetlibrary.ru/book/46471/ogl.shtml

Ivannikov, V. A. (2014). Analysis of motivation from the viewpoint of the activity theory. National Psychological Journal, 13(1), 49-56. https://doi.org/10.11621/npj.2014.0105

Kudrin, B. I. (2002). Mathematics of cenoses: species, rank-type, rank-by-parameter hyperbolic H-distributions and the laws of Lotka, Zipf, Pareto, Mandelbrot. Philosophical Foundations of Technetics. Novomoskovsk: Center for System Research., 19, 357-413. Retrieved from http://www.kudrinbi.ru/public/10524/index.htm

Leontiev, A. N. (1983). The chosen ones psychological works (V. V. Davydov \& V. P. Zinchenko, Eds.). Pedagogy. Retrieved from http://yanko.lib.ru/books/psycho/leontyev-psychology.htm

Leontiev, D. A. (1993). The system-semantic nature and functions of the motive. Bulletin of the Moscow University, 14(2), 73-82.

Leontiev, V. G. (2002). Motivation and psychological mechanisms of its formation: monograph. Novosibirsk: Publishing house "Novosibirsk Polygraph Combine".

Leontiev, D. A. (2016). A. N. Leontiev's concept of motive and the issue of the quality of motivation. Moscow University Psychology Bulletin, 2016(2), 3-18. https://doi.org/10.11621/vsp.2016.02.03

Orlov, Y. M. (1984). Need-motivational factors of the effectiveness of educational activities of university students. Retrieved from http://childpsy.ru/upload/dissertations/\%CE\%F0\%EB\%EE\%E2_\%DE_\%CC_2_1984.htm

Pareto, V. (2007). Compendio di sociologia generale / a cura di G. Farina. [Compendium of general sociology / edited by G. Farina] Publishing House of the Higher School of Economics. Retrieved from https://id.hse.ru/data/2010/11/03/12233 48293/1.3.pdf 